\title{
The normal dimensions of the sella turcica in Jordanians: a study on lateral cephalograms
}

\author{
J.H. Abu Ghaida ${ }^{1}$, A.J. Mistareehi ${ }^{1}$, A.G. Mustafa' ${ }^{1}$, S.M.A. Mistarihi' ${ }^{2}$, H.H. Ghozlan ${ }^{1}$ \\ ${ }^{1}$ Department of Anatomy, Faculty of Medicine, Jordan University of Science and Technology, Jordan \\ ${ }^{2}$ Royal Medical Services, Jordanian Armed Forces. King Hussein Medical Centre, Jordan
}

[Received: 21 February 2016; Accepted: 6 June 2016]

\begin{abstract}
Background: The sella turcica is an important anatomic and radiologic entity. The dimensions of the sella turcica vary greatly in normal individuals and are influenced by genetic and local factors. The main objective of this study is to build up a normative database of the dimensions of the sella turcica in the Jordanian population. Materials and methods: For this purpose 509 computed cephalograms of 252 male and 257 female healthy Jordanians aged 10-40 years were collected and divided into two adolescent and adult age-groups for both genders. Viewbox 3 software was used to determine linear dimensions and area of the sella turcica. Results: Our results showed that the overall values for width, length, height, area, and aperture (interclinoid distance) were 8.72, 7.68, 6.25, 40.80, 3.92, and 8.67, $7.42,6.38,41.26,3.68 \mathrm{~mm}\left(\mathrm{~mm}^{2}\right)$ for males and females, respectively. Significant differences were found between adult male group on one hand and adolescent female group and adult female group on the other hand. Between age categories and within male and female groups, sella parameters were significantly different between adolescent and adult age-groups.

Conclusions: Our data clearly confirm the classical notion of general trend of increase in parameters with age, irrespective of gender, with the area scoring the highest increase, and the height in females and length in males contributing most obviously to this trend. The aperture appears to decrease in females while it increases in males as adulthood is reached. This seems to reflect differential growth of the pituitary gland under neurohormonal effects. (Folia Morphol, 2017; 76, 1: 1-9)
\end{abstract}

Key words: morphometry, interclinoid distance, Jordan

\section{INTRODUCTION}

As early as 1693, the Latin term: sella turcica has been coined in Blancard's dictionary as the Turkish saddle. In particular, the resemblance to the Turkish saddle stems from its high front and back support [41]. The sella turcica is composed of the tuberculum sellae, the hypophyseal fossa, and the dorsum sellae, and houses the pituitary gland [16]. From an embryo- logic point of view, the sella turcica develops in the most anterior part of the germ sheet [39]. It should be noted that the anterior and posterior walls of the sella turcica have different origins [38]. The development of the pituitary gland is closely coordinated with that of the sella [50]. Postnatally, the contour of the anterior wall of the sella turcica remains stable after 6 years of age, and is used as a superimposing 
structure in cephalometric growth analysis. However, the floor and dorsal wall of the sella undergo resorption until the age of 16-17 years and 14-15 years in boys and girls, respectively [36]. Based on studies on monozygotic twins, the shape and dimensions of the sella turcica are not only genetically determined, but are also locally influenced [53].

Clinicians need a baseline for normal radiographic anatomy and variability of the sella turcica to be able to better recognise and effectively investigate changes that may reflect pathological conditions, even prior to the onset of symptoms of pituitary or craniofacial syndromes [3]. Indeed, changes of the sella are often the only indication of pathological cranial abnormality [37]. Moreover, morphometric knowledge about the sella turcica is mandatory for neurosurgeons in order to choose the best operative approach [47]. Enlargement of the sella is the most frequent pathological finding, although usually is not accompanied by bone erosion [14]. On the other hand, small sella, although less likely to occur, can also be seen [5]. Moreover, several pathological conditions are associated with maldevelopment of the sella and pituitary gland. Deviations of the anterior wall of the sella seem to be associated with deviations of the fronto-nasal field. On the other hand, deviations of the posterior wall are usually associated with malformations of posterior neurological structures [30].

Measurements of the sella have been described as early as 1923 [8]. Great variations have been reported in the measurements of length, depth, and diameter in both sexes with discrepancies between various measurements in different studies attributed to the use of different landmarks and different radiographic techniques. Accepted normal maximum dimensions of the sella turcica are $16 \mathrm{~mm}$ for the anteroposterior diameter and $12 \mathrm{~mm}$ for the depth [48].

Most investigators agree that growth of the sella decreases rapidly after the first years of life and increases in a parallel manner to growth spurt phases e.g. adolescence, with the height of the sella seeming to be the most representative parameter of change, but it slows down and ceases in early adulthood. This growth of the sella affects linear dimensions, size, and area of the sella, and appears to follow the somatic growth pattern, possibly related to the function of the anterior lobe of the pituitary gland, irrespective of sex and skeletal type [1, 3, 5].
As for the impact of gender, Silverman [52] showed that males exhibit larger sellae than females, except during puberty. Similar results were reported $[12,26]$. In specific terms, only the length displayed gender-dependent differences i.e. larger in males [5]. Similarly, the area of the sella turcica was found to be slightly larger in males than females up to puberty, after which the size was greater in females [22]. On the other hand, height and width were significantly larger in females $[3,11]$. Moreover, no gender differences could be documented including sella height, length, depth, and size $[1,19,43]$.

Different studies on the dimensions of the sella turcica have been performed in different populations around the globe. Interestingly, linear dimensions of the sella turcica in Saudis were on average 1-3 $\mathrm{mm}$ larger than other studies [1]. Norwegians showed smaller dimensions by $0.2-1 \mathrm{~mm}$ [5]. However, sella dimensions in Africans were reported to be similar in Caucasians [59]. More in this context, several studies were concerned, at least in part, in correlating the dimensions of the sella turcica with the skeletal type. On one hand, linear parameters of the sella turcica did not show significant differences in relation to skeletal types [58]. On the other hand, Alkofide [1] reported that linear dimensions, but not the area, differed significantly between skeletal types, with type III showing the greatest values.

One interesting aspect of the sella turcica relates to the interclinoid distance. It has been stated that osseous bridges between the clinoid processes may influence the shape of the sella [25]. Bridging was classified as type $A$ : ribbon-like fusion or type $B$ : meeting of clinoid processes [6]. In this regard, bridge type A (ribbon-like) predominates [27]. Taking this into consideration, roofing, calcification of the diaphragma sellae, or bridging in the absence of pathology is considered a normal variant of the sella [29]. Leonardi et al. [33] introduced a standardised scoring scale of bridging as Class I, II, and III. Age and gender did not significantly alter the calcification of the interclinoid ligament, and bridging was reported to range $3.8-13 \%$ in healthy subjects $[9,5,27]$. In another view, bridging may be caused by superimposition rather than fusion of the clinoid processes [6], or predisposed developmentally by laying down of a cartilage primordium [40], or is related to the course of the internal carotid artery [44]. 
The goals of this study can be described as:

1. To build up a database of normal linear measurements the sella turcica including length, width and depth in addition to area and interclinoid distance in different age-groups representing adolescence, early adulthood, and late adulthood categories in both gender.

2. To study age-, and gender-dependent differences in measurements of the sella turcica and provide a trend of significant change of these parameters.

3. To correlate the measurements of the sella turcica in Jordanian population with those measurements published in literature in other countries and races.

4. To provide possible explanation for significant differences between measurements of the sella turcica in different age-groups and in both genders within the Jordanian population and between Jordanian population and other populations around the world.

5. To propose ideas for future research related to this topic.

\section{MATERIALS AND METHODS}

\section{Sample of study}

The study sample consists of 509 computed lateral cephalograms of Jordanian subjects which were taken in a referral hospital in Amman-Jordan in the period from the beginning of 2013 to the end of 2014 . The subjects were 252 males and 257 females, aged 10-40 years, who were seeking dental treatment only but otherwise healthy with no diagnosed syndromes, surgical interventions, clefts or other malformations. As inclusion criteria the all computed lateral cephalograms exhibited the following features:

1. Clear reference ruler to correct the magnification of the images.

2. Good quality with clear radiographic landmarks and sella turcica outline needed for the measurement of the parameters of the sella turcica. Malocclusion and skeletal classes were not considered as criteria for the selection of the radiographs.

\section{Measurements}

To avoid bias during the measurements all the cephalograms were numbered at random, and the information related to the patients was concealed. All further work with the cephalograms was performed using these number codes, without revealing the data related the patient. Only after all measurements were completely done and archived, corresponding personal data for each number code was taken into consideration for data grouping and statistical analysis. The cephalograms were scanned at $300 \mathrm{dpi}$, and software Viewbox 3 (dHAL Software, Kifissia, Greece) was used to study the sella turcica.

The following points in the sella turcica were first determined and digitised [3, 52]:

1. Orbitale: the most inferior point of the orbital floor below the centre of the eye.

2. Porion: the most superior point of the external auditory meatus. Alternatively, the superior fossa of the temporomandibular joint, which lies at the same level, was used as a substitute.

3. Tuberculum sellae (TS): the anterior boundary of the sella turcica.

4. Posterior clinoid process (PClin).

5. Tip of the anterior clinoid process.

6. Tip of the posterior clinoid process.

The first two points were used to construct Frankfort horizontal (FH) line. The contour of the sella turcica was traced from TS to PClin, and 9 additional, equally spaced points along the internal contour of the sella turcica were defined. On the basis of these 11 points the computer software was used to define the following points (Fig. 1):

1. Sella most anterior: the most anterior point in the inner contour of the sella turcica.

2. Sella most posterior: the most posterior point in the inner contour of the sella turcica.

3. Sella floor: the lower most point in the inner contour of the sella turcica.

4. Midpoint between TS and PCLin. The following measurements were calculated using $\mathrm{FH}$ line as the reference and after adjusting the magnification of the radiographs:

1. Sella width: the largest antero-posterior dimension from sella posterior to sella anterior.

2. Sella length: the distance from TS to PClin.

3. Sella height: the vertical distance from the sella floor to the midpoint between PClin and TS.

4. Sella area: the area included by the outline of the sella and capped by a line joining PClin and TS.

5. Sella aperture (interclinoid distance): the distance from the tip of anterior clinoid process to the tip of the posterior clinoid process.

\section{Statistical analysis}

The cephalograms were categorised into two agegroups for both genders. The groups were selected to represent adolescent phase: 10-19 years old (total 


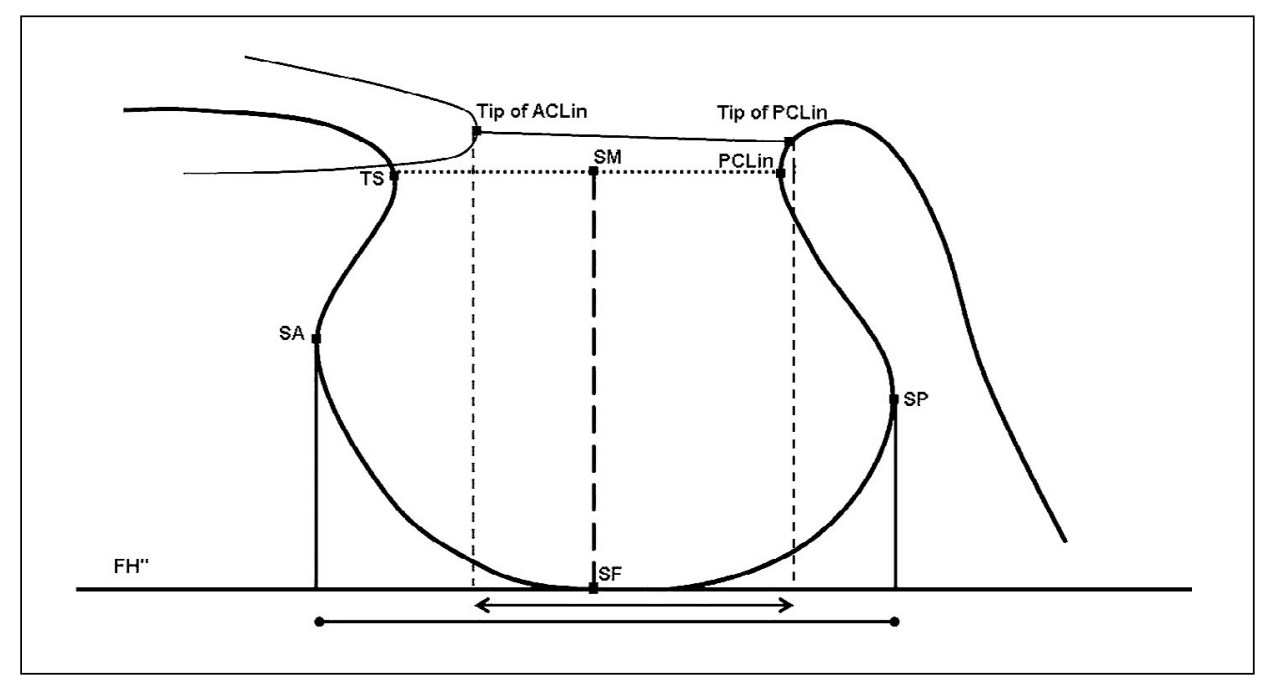

Figure 1. Measurements of the sella turcica. FH" line — line parallel to Frankfurt horizontal line; TS — tuberculum sellae; SA — sella most anterior point; SF — sella floor; SP — sella most posterior point; ACLin — anterior clinoid process; PCLin — posterior clinoid process; SM — sella median point; square dots — sella length; rounded ends line — sella width; dashed line — sella height; double arrowed line — aperture (interclinoid distance) (According to: Andredaki et al., 2007 with modifications).

number 396: 207 males, 189 females), and adulthood phase: 20-40 years old (total number 113: 45 males, 78 females), as advised by the World Health Organisation (www.WHO.int). For each age-group and in both genders the basic statistics were performed for linear measurements and area of the sella turcica. Measurements were calculated to the nearest $0.01 \mathrm{~mm}$. Statistical analysis of data was performed by transferring the data to a scientific statistical programme (SPSS Inc., Chicago, Illinois, USA). Correlation tests were performed to define statistically significant differences related to gender, age, and all numerical measurements included in this study using the Student ' $s$ t-test for independent data with significance level of $5 \%(p<0.05)$.

\section{Error analysis}

In accordance with Houston [24], the accuracy and reproducibility of the measurements were confirmed by repeating the measurements for randomly selected 103 cephalograms by the same operator on 3 separate occasions with at least 1 week interval between the repeated measurements. Original and repeated sets of measurements were analysed for significance of differences, coefficient of reliability, and variance.

\section{RESULTS}

\section{Basal values}

Table 1 shows the measured values for the linear dimensions and area for the overall test sample, the overall male and female groups, the overall adoles- cent and adult age-groups, and for adolescent male and female groups and adolescent male and female groups. All values are expressed as mean (standard deviation [minimum value-maximum value], linear dimensions in $\mathrm{mm}$, area in $\mathrm{mm}^{2}$.

\section{Correlations}

No significant differences were evxident in mean overall values of all linear measurements and area of the sella turcica between genders, or between adolescent male and female groups $(p>0.05)$. However, differences between means of width, length, aperture, and area, but not height were significant between adult male and adult female age-groups $(p<0.05)$.

Differences between means of overall adolescent and adult age-groups were insignificant.

Differences between means of adolescent and adult female age-groups were significant for width, height, aperture, and area, but not for height.

Differences between adolescent and adult male age-groups were significant for width, length, height, and area, but not for aperture.

\section{Error calculation}

As shown in Table 2, the statistical analysis of the original and repeated measurement using paired $t$-test revealed no significant differences $(p>0.05)$ between the two sets of measurements. No systematic error was detected between the original and repeated measurements. Differences between original 
Table 1. Descriptive statistics of the morphometric parameters of sella turcica

\begin{tabular}{lccccc}
\hline Studied group & \multicolumn{5}{c}{ Parameters } \\
\cline { 2 - 6 } & Width & Length & Height & Area & Aperture \\
\hline Total sample $(\mathrm{n}=509)$ & $8.69 \pm 1.34$ & $7.55 \pm 1.72$ & $6.32 \pm 1.03$ & $41.03 \pm 10.57$ & $3.80 \pm 1.67$ \\
& $(5.80-13.90)$ & $(2.4-13.7)$ & $(3.7-11.2)$ & $(16.5-84.6)$ & $(0.0-9.3)$ \\
Males $(\mathrm{n}=$ 252) & $8.72 \pm 1.42$ & $7.68 \pm 1.77$ & $6.25 \pm 1.09$ & $40.80 \pm 11.48$ & $3.92 \pm 1.57$ \\
& $(6.2-13.9)$ & $(4.0-13.7)$ & $(3.7-11.2)$ & $(16.5-84.6)$ & $(0.0-8.7)$ \\
Females $(\mathrm{n}=257)$ & $8.67 \pm 1.26$ & $7.42 \pm 1.66$ & $6.38 \pm 0.96$ & $41.26 \pm 9.62$ & $3.68 \pm 1.76$ \\
& $(6.0-13.0)$ & $(2.0-13.0)$ & $(4.0-8.6)$ & $(17.8-70.8)$ & $(0.0-9.3)$ \\
Adolescents $(\mathrm{n}=396)$ & $8.51 \pm 1.29$ & $7.44 \pm 1.66$ & $6.16 \pm 0.96$ & $39.03 \pm 9.75$ & $3.84 \pm 1.61$ \\
& $(6.0-14.0)$ & $(3.0-14.0)$ & $(3.7-9.1)$ & $(16.5-73.5)$ & $(0.0-9.3)$ \\
Adults $(\mathrm{n}=113)$ & $9.32 \pm 1.32$ & $7.94 \pm 1.87$ & $6.87 \pm 1.06$ & $48.04 \pm 10.4$ & $3.64 \pm 1.86$ \\
& $(6.0-13.4)$ & $(2.4-13.2)$ & $(4.0-11.2)$ & $(17.8-84.6)$ & $(0.0-8.1)$ \\
Male adolescents $(\mathrm{n}=207)$ & $8.48 \pm 1.29$ & $7.45 \pm 1.65$ & $6.08 \pm 0.97$ & $38.53 \pm 10.03$ & $3.86 \pm 1.53$ \\
& $(6.2-13.8)$ & $(4.0-13.7)$ & $(3.7-9.1)$ & $(16.5-73.5)$ & $(0.0-8.7)$ \\
Female adolescents $(\mathrm{n}=189)$ & $8.55 \pm 1.3$ & $7.43 \pm 1.67$ & $6.24 \pm 0.95$ & $39.57 \pm 9.43$ & $3.82 \pm 1.69$ \\
& $(6.0-13.0)$ & $(3.0-13.0)$ & $(4.0-8.6)$ & $(18.5-70.8)$ & $(0.0-9.3)$ \\
Male adults $(\mathrm{n}=45)$ & $9.81 \pm 1.48$ & $8.75 \pm 1.92$ & $7.05 \pm 1.24$ & $51.2 \pm 12.09$ & $4.17 \pm 1.7$ \\
& $(7.4-13.4)$ & $(4.7-13.2)$ & $(4.7-11.2)$ & $(26.7-84.6)$ & $(1.7-8.1)$ \\
Female adults $(\mathrm{n}=68)$ & $9.0 \pm 1.1$ & $7.39 \pm 1.64$ & $6.75 \pm 0.9$ & $45.95 \pm 8.61$ & $3.29 \pm 1.89$ \\
& $(6.0-12.0)$ & $(2.4-10.9)$ & $(4.0-8.6)$ & $(17.8-64.6)$ & $(0.0-7.3)$ \\
\hline
\end{tabular}

Table 2. Error analysis of the morphometric measurements

\begin{tabular}{lcc}
\hline Parameter & $\begin{array}{c}\text { Original } \\
\text { measurements }\end{array}$ & $\begin{array}{c}\text { Repeated } \\
\text { measurements } \\
(\mathbf{n}=\mathbf{1 0 3})\end{array}$ \\
\hline Width & $8.17 \pm 0.13$ & $8.53 \pm 0.14$ \\
Length & $7.07 \pm 0.16$ & $7.45 \pm 0.18$ \\
Height & $6.07 \pm 0.09$ & $6.50 \pm 0.10$ \\
Area & $38.54 \pm 1.03$ & $41.54 \pm 1.11$ \\
Aperture & $4.13 \pm 0.17$ & $3.64 \pm 0.16$ \\
\hline
\end{tabular}

and repeated measurements ranged $0.2-0.6 \mathrm{~mm}$ for the linear parameters and $0.0-2.9 \mathrm{~mm}^{2}$ for the sella area. The coefficients of reliability were as follows: width $=91.8$, length $=92.5$, height $=92.1$, area $=93.9$, and aperture $=84.8$.

The random error (the square root of half of the variance of the difference between duplicate measurements) ranged $0.052-0.093 \mathrm{~mm}$.

\section{DISCUSSION}

The importance of carrying out this work is selfexplanatory. This is clearly based on academic and applied clinical grounds. However, discrepancies between the basal values of various measurements of the sella turcica in different studies throughout the literature may pose difficulties for researchers and clinicians dealing with this particular subject. The sella turcica has been studied using different approaches including microsurgery, e.g. [8], radiographs on dry skulls e.g. [34], lateral cephalograms, e.g. [3], computed tomography, e.g. [48], and magnetic resonance imaging, e.g. [57]. Radiographs of the normal sella were reported to provide data that coincide well with data obtained from direct measurements on autopsy specimens [8], and provide a high sensitivity of $67-77 \%$ for detection sellar changes [18]. Computed tomography and magnetic resonance imaging have been shown to provide much greater sensitivity than cephalograms for detection of pituitary pathology [31]. Nevertheless, the relevance of radiological studies remains valid [15, 57].

The data we obtained can be regarded as a normative database of linear dimensions and area of the sella turcica, and is the first comprehensive study conducted in Jordan, to the best of our knowledge, so far. In this regard, our data correlate well with respective data already published e.g. [3], who also made use of Viewbox 3 software, and adopted the same definitions of measurement parameters. On the other hand, greater values were often reported e.g. [1, 5, $15,21,46,48,58,59]$. It can be expected that in cases where the sella is normally tilted, any measurement of the height and length without referring to the $\mathrm{FH}$ line will result in different readings. Similarly, if the width has been defined as the distance from the TS 


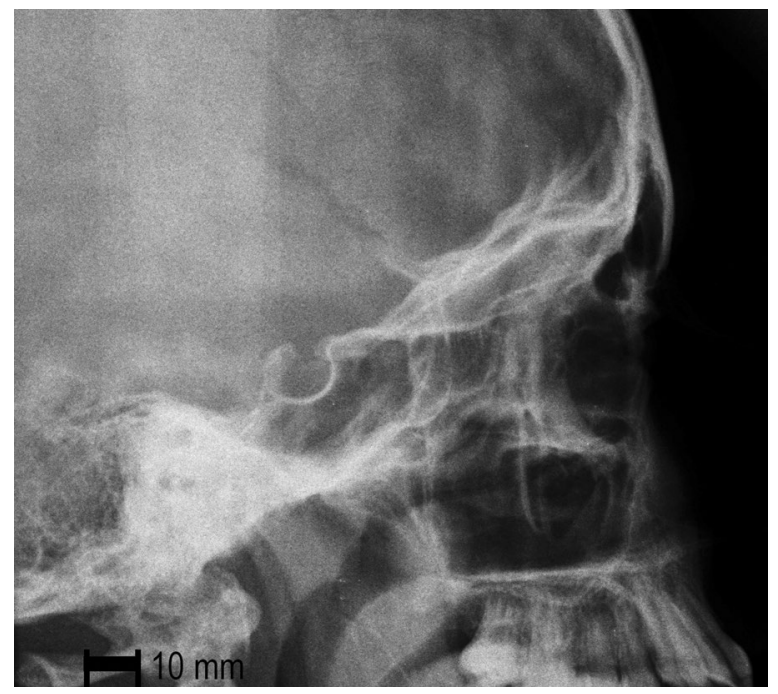

Figure 2. Lateral cephalogram for a male adolescent.

or a point just below the TS to the most posterior post on the contour of the sella different readings will be invariably obtained. Consequently, simple multiplication of width and height to calculate the area will result in higher values. In our study, however, referring to the $\mathrm{FH}$ line as a reference for linear measurements, and relying on 11 points along theinner contour of the sella to calculate the area, in addition to correction of the magnification factor of cephalograms result in more realistic and accurate, yet smaller values. Our error analysis speaks clearly in favour of our technique making use of sophisticated computer software for reliable and reproducible morphometric analysis of bony structures studied on cephalograms. More to this particular aspect, although significant differences have been suggested to exist between different population groups and between races [1,58], it must be seriously taken into consideration, that the above-mentioned factors should always be considered, if relevant comparisons of data are to be made. Comparing our results with Andredaki's et al. [3] speaks most probably against the existence of significant differences between different populations. A racial impact, however, cannot be totally excluded in view of absence of standardised comparisons between races. Moreover, it is obvious that the linear measurements and area of the sella turcica in our study, as well as in other studies, show a striking wide range between minimal and maximal basal values, which clearly point out to the great variation in normal data, as already stated [7]. This may make the distinction between normal and pathological conditions depending solely on mean values rather difficult. A similar conclusion has been made by Chilton et al. [12].

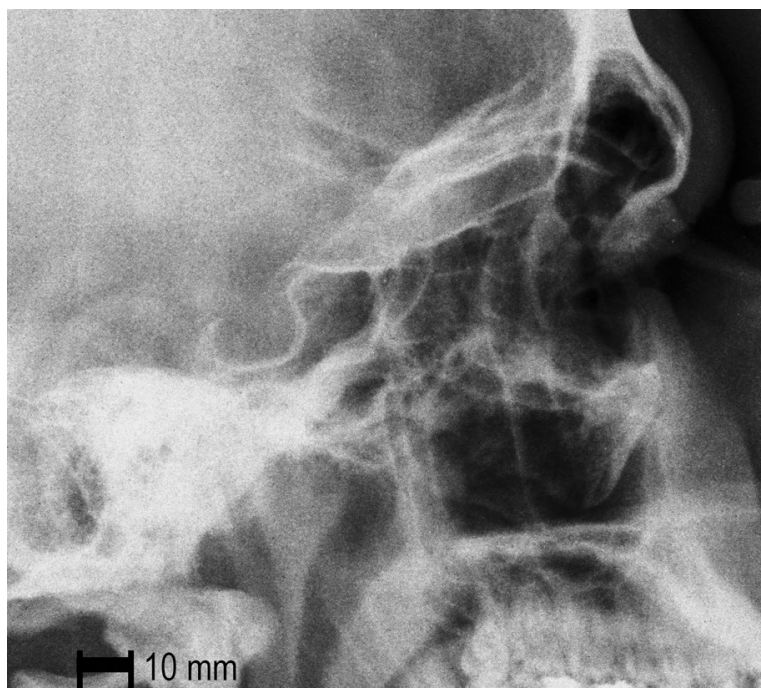

Figure 3. Lateral cephalogram for a male adult.

With respect to age-dependent changes in linear parameters of the sella turcica, our data clearly confirm the classical notion of the trend of increase in parameters with age, irrespective of gender [20]. Expressed in percentages, our data show that linear measurements and area of the sella turcica increased $7-12 \%$ and $23 \%$ between adolescence and adulthood phases, respectively. The height shows the most obvious increase. As for the sella aperture, this parameter increases by $8 \%$ in males, but decreases by $14 \%$ in females, when adolescent and adult groups are compared. Adult males show strikingly wider mean values with statistically highly significant difference of $27 \%$, with total absence of complete sellar bridging. It has been previously shown that changes of the sella aperture are significantly correlated with changes of area and perimeter of the sella turcica [2]. As for our results (Figs. 2-5), and dissected in terms of gender, a differential pattern of change of sellar parameters between males and females seems to exist. In males, linear parameters increase by $16-18 \%$, with the length lying on the summit of increase, while in females only an increase increment of $5-8 \%$ is evident, with the height scoring highest, and the length remaining almost unchanged. As for the area, males show a 33\% increase versus $16 \%$ increase in females. Parallel to these changes, the aperture increases by $8 \%$ in males, while it narrows, decreasing by $14 \%$ in females. So while the sella expands in all directions in males with most obvious increase in the length (Figs. 2, 3), the height seems to be the major factor increasing the area in females as the sella floor deepens vertically and 


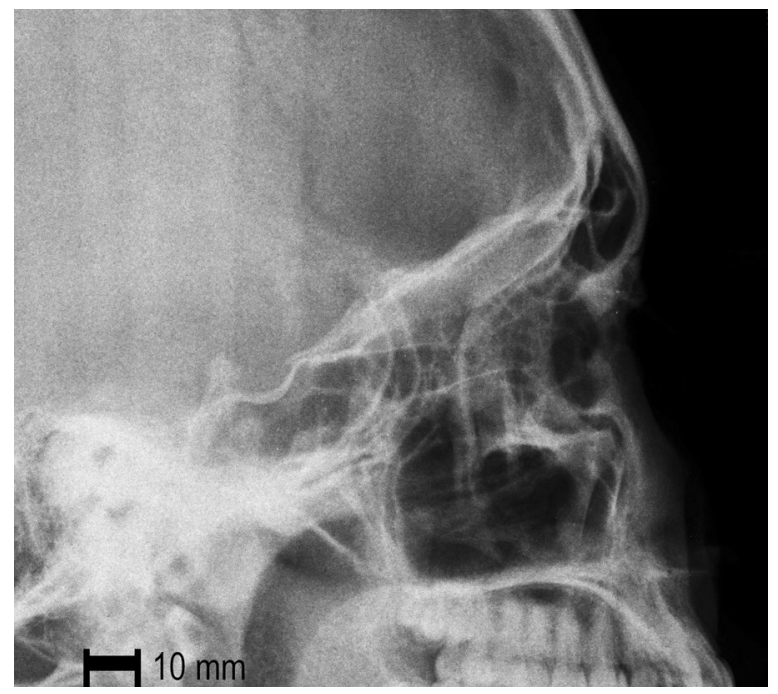

Figure 4. Lateral cephalogram for female adolescent.

the sella becomes taller (Figs. 4, 5). Correlating means of female sellar parameters between adolescent and adult groups, all parameters show significant changes, except for the length. In males, on the other hand, all parameters show significant changes, except for the aperture. The existing literature shows that continuing increase in the area and size of the sella is evident as the individual ages in both sexes, but more in males $[1,10,11,19,22,26,42,43,49,55,58]$. In specific terms, the anteroposterior diameter, depth, and area increase within 13-25 and 26-40 years of age, and decrease or remain constant between 41 and 55 years of age $[4,10,22,28,32,51]$. In a recent study, only depth of the sella has been shown to exhibit significant agedependent differences with reference to sex [54]. This change obviously follows the somatic growth pattern and is suggested to be related to the function of the anterior lobe of the pituitary gland [5, 13, 45, 52]. It has been already stated that the morphometric analysis of the sella turcica correlates well with the pituitary gland [57]. Interestingly, when age-dependent changes of the sella turcica are translated in terms of pituitary gland dimensions, changes in pituitary size as a function of age were shown to be mainly due to changes in gland height reaching a peak at 20-29 years of age, but not length or width, which may reflect normal age-dependent neuroendocrine differences $[17,23,35,56]$.

Regarding gender-dependent differences our results clearly confirm the general notion that significant correlation between gender and sellar dimensions are lacking, but only in an age-dependent differential pattern. This differential behaviour has been already

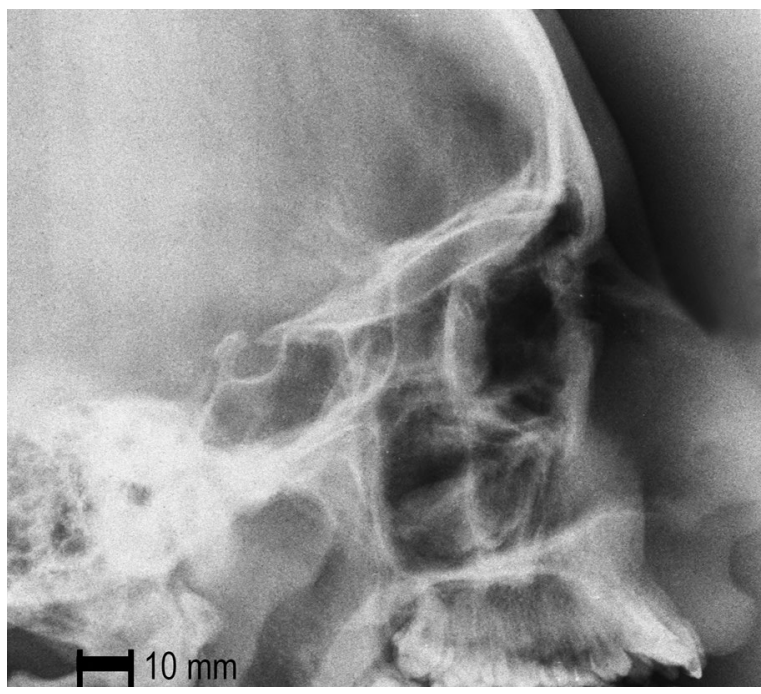

Figure 5. Lateral cephalogram for a female adult.

published regarding sellar length [5] and sellar height [11]. The statistical analysis of our data reveals that only the means of all parameters, except for the height, show significant differences between adult male group and adult female group. Although we show that males have larger sellae than females, as frequently stated $[12,26,52]$, this difference becomes first significant in adulthood. Indeed, and in agreement with our results, equalization of sella parameters at puberty in males and females was already described $[1,13,45]$.

\section{CONCLUSIONS}

In the light of our results we suggest that future research in this regard should include magnetic resonance imaging studies of the pituitary gland dimensions, studies of the sphenoid air sinuses, cavernous sinuses, and the intracranial part of the internal carotid arteries in different age-groups in both genders. Measurements of the sella turcica should be extended to include early childhood i.e. below 10 years of age and postmenopausal and elderly subjects above 50 years of age. Moreover, the characterisation of the shape of the sella and description of age- and genderdependent differences of shape should be coupled to linear and area measurements. These measurements should be also compared to known pathological conditions of the pituitary gland and craniofacial region. The specific question should be addressed whether one or more specific parameter of the sella turcica can be regarded as a relatively reliable indicator of normality and/or abnormality in view of the wide range of normal values. 


\section{Acknowledgments}

The authors wish to express their deep gratitude to Mr. Saleem Rabadi, Art Director, Vast Technologies, Amman-Jordan and Mr. Noor Aldean Sleaman Sbaihat, Radiology Technician, Royal Medical Services, for their professional help in collecting and processing the radiographs and diagrams.

This work is part of the MSc Thesis submitted by Mr. Anas Mistarehi in partial fulfilment of the requirements for obtaining the MSc Degree in Anatomy by the faculty of Higher Studies at the Jordan University of Science and Technology in August 2015.

This work has been supported by Grant No: $89 / 2015$ by the Faculty of Research at Jordan University of Science and Technology.

\section{REFERENCES}

1. Alkofide EA. The shape and size of the sella turcica in skeletal Class I, Class II, and Class III Saudi subjects. Eur J Orthod. 2007; 29(5): 457-463, doi:10.1093/ejo/cjm049, indexed in Pubmed: 17693429.

2. Ananthi KS, Agarwel $\mathrm{SK}$, Komari $\mathrm{MCl}$. Abnormal small Sella - a case report. J Anat Soc India. 2009; 58: 13-15.

3. Andredaki M, Koumantanou A, Dorotheou D, et al. A cephalometric morphometric study of the sella turcica. Eur J Orthod. 2007; 29(5): 449-456, doi:10.1093/ejo/ cjm048, indexed in Pubmed: 17974535.

4. Agrawal GN, Newton GB. Radiological study of normal Sella turcica in Indians. Journal Indian MA. 1968; 51: 519-522.

5. Axelsson S, Storhaug K, Kjaer I. Post-natal size and morphology of the sella turcica. Longitudinal cephalometric standards for Norwegians between 6 and 21 years of age. Eur J Orthod. 2004; 26(6): 597-604, doi: 10.1093/ ejo/26.6.597, indexed in Pubmed: 15650069.

6. Becktor JP, Einersen S, Kjaer I. A sella turcica bridge in subjects with severe craniofacial deviations. Eur J Orthod. 2000; 22(1): 69-74, doi:10.1093/ejo/22.1.69, indexed in Pubmed: 10721247.

7. Brock-Jacobsen MT, Pallisgaard C, Kjaer I. The morphology of the sella turcica in monozygotic twins. Twin Res Hum Genet. 2009; 12(6): 598-604, doi:10.1375/twin.12.6.598, indexed in Pubmed: 19943723.

8. Camp J. The normal and pathologic anatomy of the Sella Turcica as revealed at necropsy. Radiology. 1923; 1(2): 65-73, doi: 10.1148/1.2.65.

9. Cederberg RA, Benson BW, Nunn M, et al. Calcification of the interclinoid and petroclinoid ligaments of sella turcica: a radiographic study of the prevalence. Orthod Craniofac Res. 2003; 6(4): 227-232, doi: 10.1034/j.16000544.2003.00243.x, indexed in Pubmed: 14606526.

10. Chavan SR, Kathole MA, Katti AS, Herekar NG. Radiological analysis of Sella turcica. Int J Recent Trends Science Technol. 2012; 4: 36-40.

11. Chauhan P, Kalra S, Mongia S, et al. Morphometric analysis of sella turcica in North Indian population: a radiological study. Int J Res Med Sciences. 2014; 2(2): 521, doi: 10.5455/2320-6012.ijrms20140529.
12. Chilton LA, Dorst JP, Garn SM. The volume of the sella turcica in children: new standards. AJR Am J Roentgenol. 1983; 140(4): 797-801, doi:10.2214/ajr.140.4.797, indexed in Pubmed: 6601392.

13. Choi WG, Hwang EH, Lee SR. The study of shape and size of normal Sella turcica in cephalometric radiographs. Korean J Oral Maxillofac Radiol. 2001; 31: 43-49.

14. De Marinis L, Bonadonna S, Bianchi A, et al. Primary empty sella. J Clin Endocrinol Metab. 2005; 90(9): 5471-5477, doi: 10.1210/jc.2005-0288, indexed in Pubmed: 15972577.

15. Denk CC, Onderoğlu S, Ilgi S, et al. Height of normal pituitary gland on MRI: differences between age groups and sexes. Okajimas Folia Anat Jpn. 1999; 76(2-3): 81-87, doi: 10.2535/ofaj1936.76.2-3_81, indexed in Pubmed: 10502959.

16. DI Chiro G, Nelson KB. The volume of the sella turcica. Am J Roentgenol Radium Ther Nucl Med. 1962; 87: 989-1008, doi: 10.1007/978-3-540-47648-1_5228, indexed in Pubmed: 13885978.

17. Doraiswamy PM, Potts JM, Axelson DA, et al. MR assessment of pituitary gland morphology in healthy volunteers: age- and gender-related differences. AJNR Am J Neuroradiol. 1992; 13(5): 1295-1299, indexed in Pubmed: 1414818.

18. Du Boulay G, Trickey S. The choice of radiological investigations in the management of tumours around the sella. Clin Radiol. 1967; 18(4): 349-365, doi: 10.1016/s00099260(67)80035-7, indexed in Pubmed: 5299682.

19. Filipovic G, Buric M, Janosevic M, et al. Radiological measuring of sella turcica's size in different malocclusions. Acta Stomatologica Naissi. 2011; 27(63): 1035-1041, doi: 10.5937/asn1163035f.

20. Fissure RL, DiChiro G. The small Sella turcica. Am J Roentgenol Radium Ther Nuc Med. 1964; 91: 996-1008.

21. Friedland B, Meazzini MC. Incidental finding of an enlarged sella turcica on a lateral cephalogram. Am J Orthod Dentofacial Orthop. 1996; 110(5): 508-512, doi: 10.1016/ s0889-5406(96)70057-4, indexed in Pubmed: 8922509.

22. Haas LL. The size of the sella turcica by age and sex. Am J Roentgenol Radium Ther Nucl Med. 1954; 72(5): 754-761, doi: 10.1007/978-3-540-47648-1_5228, indexed in Pubmed: 13207487.

23. Hayakawa K, Konishi Y, Matsuda T, et al. Development and aging of brain midline structures: assessment with MR imaging. Radiology. 1989; 172(1): 171-177, doi: 10.1148/ radiology.172.1.2740500, indexed in Pubmed: 2740500.

24. Houston WJ. The analysis of errors in orthodontic measurements. Am J Orthod. 1983; 83(5): 382-390, doi: 10.1016/0002-9416(83)90322-6, indexed in Pubmed: 6573846 .

25. Inoue T, Rhoton AL, Theele D, et al. Surgical approaches to the cavernous sinus: a microsurgical study. Neurosurgery. 1990; 26(6): 903-932, doi:10.1227/00006123199006000-00001, indexed in Pubmed: 2362670.

26. Israel H. Continuing growth in sella turcica with age. Am J Roentgenol Radium Ther Nucl Med. 1970; 108(3): 516-527, doi: 10.2214/ajr.108.3.516, indexed in Pubmed: 5415926.

27. Jones RM, Faqir A, Millett DT, et al. Bridging and dimensions of sella turcica in subjects treated by surgical-ortho- 
dontic means or orthodontics only. Angle Orthod. 2005; 75(5): 714-718, doi: 10.1043/0003-3219(2005)75[714:BADOST]2.0.CO;2, indexed in Pubmed: 16279819.

28. Joplin GF, Fraser R. The radiological anatomy of the human pituitary. In: Ciba Foundation. Symposium - Human Pituitary Hormones (Colloquia on Endocrinology). John Wiley \& Sons, Ltd. 1960; 13: 9-24.

29. Kantor ML, Norton LA. Normal radiographic anatomy and common anomalies seen in cephalometric films. Am J Orthod Dentofacial Orthop. 1987; 91(5): 414-426, doi: 10.1016/0889-5406(87)90394-5, indexed in Pubmed: 3554978.

30. Kjær I. Sella turcica morphology and the pituitary gland: a new contribution to craniofacial diagnostics based on histology and neuroradiology. Eur J Orthod. 2015; 37(1): 28-36, doi: 10.1093/ejo/cjs091, indexed in Pubmed: 23159420.

31. Kricheff II. The radiologic diagnosis of pituitary adenoma: an overview. Radiology. 1979; 131(1): 263-265, doi: 10.1148/131.1.263, indexed in Pubmed:424601.

32. Lal BN, Tondon BN, Ghosh SK, et al. Radiological study of normal Sella turcica. Indian J Radiol 19. 1965; 29: 84-90.

33. Leonardi $R$, Barbato $E$, Vichi $M$, et al. A sella turcica bridge in subjects with dental anomalies. Eur J Orthod. 2006; 28(6): 580-585, doi:10.1093/ejo/cjl032, indexed in Pubmed: 16954179.

34. Lung J, Tisch-rottensteiner KF. Ueber Form und Formvarianten der Sella Turcica. Verh Anat Ges. 1977; 71: 1279-1282.

35. Lurie SN, Doraiswamy PM, Husain MM, et al. In vivo assessment of pituitary gland volume with magnetic resonance imaging: the effect of age. J Clin Endocrinol Metab. 1990; 71(2): 505-508, doi: 10.1210/jcem-71-2-505, indexed in Pubmed: 2380345.

36. Melsen B. The cranial base. The post natal development of the cranial base studied historically on human autopsy material. Acta Odontologica Scandinavica. 1974; 32: 57-71.

37. Meschan I. An atlas of anatomy basic to radiology, WB Sounders, Philadelphia, 1975; pp. 343-348.

38. Miletich I, Sharpe PT. Neural crest contribution to mammalian tooth formation. Birth Defects Res. C Embryo Today. 2004; 72(2): 200-212, doi: 10.1002/bdrc.20012, indexed in Pubmed: 15269893.

39. Müller F, O'Rahilly R. The prechordal plate, the rostral end of the notochord and nearby median features in staged human embryos. Cells Tissues Organs (Print). 2003; 173(1): 1-20, doi: 68214, indexed in Pubmed: 12566624.

40. Muller E. Die Bedeutung der Sellabruecke fur das Auge. Klin Monatsbl Augenheilkd. 1952; 720: 298-302.

41. Mutluer S. Sella turcica. Childs Nerv Syst. 2006; 22(4): 333, doi: 10.1007/s00381-006-1278-x, indexed in Pubmed: 16514527.

42. Najim AA, Al-Nakib L. A cephalometric study of Sella turcica size and morphology among young Iraqi normal population in comparison to patients with maxillary malposed canine. J Bagh Colleage Dentistry. 2011; 23: 53-58.

43. Osunwoke EA, Mokwe CR, Amah-tariah FS. Radiologic measurements of the sella turcica in an adult Nigerian population. Int J Pharmacol Res. 2014; 4: 115-117.
44. Platzer W. [Anatomy of taenia interclinoidea and its relation to the internal carotid artery]. Fortschr Geb Rontgenstr Nuklearmed. 1957; 87(5): 613-616, doi: 10.1007/978-3642-29664-2, indexed in Pubmed: 13490616.

45. Preston CB. Pituitary fossa size and facial type. Am J Orthod. 1979; 75(3): 259-263, doi: 10.1016/00029416(79)90273-2, indexed in Pubmed: 285608.

46. Quakinine JE, Hardy J. Microsurgical anatomy of the pituitary gland and the sellar region: the pituitary gland. Am Surgeon. 1987; 53: 285-290.

47. Renn WH, Rhoton AL. Microsurgical anatomy of the sellar region. J Neurosurg. 1975; 43(3): 288-298, doi: 10.3171/ jns.1975.43.3.0288, indexed in Pubmed: 1151464.

48. Ruiz CR, Wafae N, Wafae C. Sella turcica morphometry using computed tomography. Eur J Anat. 2008; 12: 47-50.

49. Shah AM, Bashir U, llyas T. The shape and size of the Sella turcica in skeletal class I, II \& III in patients presenting at Islamic international dental hospital, Islamabad. Pakistan Oral Dental J. 2011; 31: 104-110.

50. Sheng HZ, Westphal H. Early steps in pituitary organogenesis. Trends Genet. 1999; 15(6): 236-240, doi: 10.1016/ s0168-9525(99)01742-4, indexed in Pubmed: 10354584.

51. Shrivastava VK. Normal anatomy of Sella turcica in Indian subjects. Indian J Radiol. 1989; 43: 102-106.

52. Silverman FN. Roentgen standards fo-size of the pituitary fossa from infancy through adolescence. Am J Roentgenol Radium Ther Nucl Med. 1957; 78(3): 451-460, indexed in Pubmed: 13458563.

53. Sniyder LH, Blank F. Studies in human inheritance. XXVII, the inheritance of the shape of the Sella turcica. Ohio J Sci. 1945; 45: 12-15.

54. Subhadra iV, Baburao S. Age and sex related morphology and morphometry of sellar region of sphenoid in prenatal and postnatal human cadavers. Int J Res Dev Health. 2013; 1: 141-148.

55. Tetradis S, Kantor ML. Prevalence of skeletal and dental anomalies and normal variants seen in cephalometric and other radiographs of orthodontic patients. Am J Orthod Dentofacial Orthop. 1999; 116(5): 572-577, doi: 10.1016/ s0889-5406(99)70191-5, indexed in Pubmed: 10547519.

56. Tsunoda A, Okuda O, Sato K. MR height of the pituitary gland as a function of age and sex: especially physiological hypertrophy in adolescence and in climacterium. AJNR Am J Neuroradiol. 1997; 18(3): 551-554, doi: 10.1002/9780470373699.speced1617, indexed in Pubmed: 9090422.

57. Venieratos D, Anagnostopoulau S, Garidou A. A new morphometric method for the Sella turcica and the hypophyseal fossa and its clinical relevance. Folia Morphol. 2005; 64(4): 240-247.

58. Yasser YA, Nahidh M, Yousif HA. Size and morphology of Sella turcica in Iraqi adults. MDG7. 2010; 23-30.

59. Zagga AD, Ahmed $H$, Tadros AA, et al. Description of the normal variants of the anatomical shapes of the sella turcica using plain radiographs: experience from Sokoto, Northwestern Nigeria. Ann Afr Med. 2008; 7(2): 77-81, doi: 10.4314/ njm.v17i3.37405, indexed in Pubmed: 19143164. 